\title{
Interactive comment on "Concomitant ocean acidification and increasing total alkalinity at a coastal site in the NW Mediterranean Sea (2007-2015)" by Lydia Kapsenberg et al.
}

Anonymous Referee \#2

Received and published: 22 November 2016

Interactive comment on "Concomitant ocean acidification and increasing total alkalinity at a coastal site in the NW Mediterranean Sea (2007 -2015) by Lydia Kapsenberg et al. Anonymous Referee \#2

The article presents, analyses, and discusses the time series of physical parameters and carbonate system properties gathered in a coastal station of the NW Mediterranean Sea and spanning nearly one decade. The analyses on different time scales of ocean acidification, responsible for changes in the marine $\mathrm{CO} 2$ system with effects on the dissolved inorganic carbon (CT), partial pressure of $\mathrm{CO} 2$ (pCO2), pHT, total alkalinity (AT) and calcium carbonate saturation states is valuable. Actually, sustained observations of inorganic carbon parameters by means of long term time series count 
on a few sites over the global oceans, and on even fewer in the Mediterranean basin, especially in the coastal area, although such shallow zones can be exposed to intense land sea interactions and to a great complexity of physical and biological processes interacting with ocean acidification. Ocean acidification in coastal zones is remarkably difficult to predict. The present paper can contribute to a better knowledge of the coastal systems vulnerability to ocean acidification, by investigating on the multiple drivers eventually working in this environment. In particular, the analysis of the time series trends (\$3.1) appears robust and the decomposition of ocean acidification into the principal drivers is appropriate and informative. The method applied for the deconvolution of pHT and pCO2, (proposed in $\S 3.2$ and 3.3,) is new for both the Med Sea and coastal regions, and provides useful indications on different processes driving ocean acidification in this site in comparison with open ocean. The discussion of CT and AT increases as the main drivers of $\mathrm{pH}$ decrease ( $\$ 4.1$ and 4.2 ) is well conducted. The proposed attribution of these two concomitant increases (AT and CT) to terrestrial inputs with changing and increasing AT and CT (riverine water and/or to groundwater springs) seems reasonable. The hypothesis is deeply discussed, although not enough supported by the correlation with low salinity (see major comments). Finally, conclusions well enhance the role of land sea interactions. In conclusion, the publication of this article in OS is worth after a few revisions (reported below).

Major Comments: 1. Discussion on drivers of AT and CT trends (line 402-439). I agree with the suggestion of Referee \#1. The description (in terms of carbonate chemistry) of the river and underground sources in the region of the Bay of Villefranche should be added for a more complete discussion.. 2. Then l'm wondering whether results (\$3.3) and discussion (§4.2) might benefit from the recent paper by Fry et al. (2015). In the paper authors calculate "Alk1", the same as normalized AT, to remove the contribution of evaporation and precipitation, and calculate "Alk2" (accounting for river AT) to remove the riverine input. This was done because Friis et al. (2003) found that misleading results are produced if normalized alkalinity is used in ocean regions receiving river outflows. ... It seems to me that you have all the necessary data (Alkm= measured

OSD

Interactive comment
Printer-friendly version

Discussion paper 
alkalinity, salinity and Alkr=river alkalinity) requested to calculate Alk2. Following the subtraction of these major processes that affects alkalinity at Point $\mathrm{B}, \mathrm{I}$ would expect: salinity- AT relationship (through the 9 years of time series) improves the positive AT anomaly disappears (or at least decreases)

C.H. Fry, T. Tyrell, M.P. Hain, N.R. Bates and E.P. Achtenberg. Analysis of global surface ocean alkalinity to determine controlling processes. Marine Chemistry, 174,46457, 2015. Friis K., Koertzinger A. and Wallace D.W.R., 2003. The salinity normalization of marine inorganic carbon chemistry data. Geophys. Res. Lett. 30 (2), 1085.

Minor comments: Lines 222-224. Temperature anomaly increased but this significance was lost with the exclusion of the year $2015 \ldots$... The sentence is not clear to me. Do you mean that excluding the year 2015 (it was exceptionally warm and SST raised to the highest values during summer) there was no increase in temperature anomaly ? and therefore the temperature increase cannot be the driver of observed changes in the carbonate system properties ? In any case please rephrase the sentence. Lines 320-322. During the transition of these processes, salinity decreases to a minimum in May, reflecting the freshwater input that dilutes AT to minimum values... Fresh water is able to dilute AT to minimum values if discharging rivers have lower AT than seawater but this might be not true in case of rivers draining carbonatic watershed (later, line 416, authors report that outflowing rivers into the Bay of Villefranche have high AT). This can be misleading, please modify. Line 325-326. Following winter CT declines due to a combination of phytoplankton bloom carbon uptake and freshwater dilution... Again I would be more cautious as freshwater dilutes if it contains lower CT ... Lines 351-357. The correlates between Point B and N Adriatic Sea suggest a common driver of changes in ocean carbonate chemistry at these two sites (possibly linked via shared watersheds of the Alps) ........ Mediterranena Sea. Could you explain and present more clearly this hypothesis?

Please also note the supplement to this comment: 
http://www.ocean-sci-discuss.net/os-2016-71/os-2016-71-RC2-supplement.pdf

Interactive comment on Ocean Sci. Discuss., doi:10.5194/os-2016-71, 2016.

OSD

Interactive

comment

Printer-friendly version

Discussion paper 